\title{
Effectiveness of multidisciplinary intervention on blood pressure control in primary health care: a randomized clinical trial
}

Regina Kuhmmer ${ }^{1,2^{*}}$, Rosmeri Kuhmmer Lazzaretti ${ }^{1,2}$, Cátia Moreira Guterres ${ }^{1}$, Fabiana Viegas Raimundo ${ }^{1,3}$, Leni Everson Araújo Leite ${ }^{1}$, Tássia Scholante Delabary', Suhelen Caon ${ }^{1}$, Gisele Alsina Nader Bastos ${ }^{1,3}$

and Carisi Anne Polanczyk $k^{1,2}$

\begin{abstract}
Background: Hypertension is a public health problem and a major risk factor for cardiovascular disease. The purpose of this study is to compare the effectiveness of a multidisciplinary program based on group and individual care versus group-only care, to promote blood pressure control in hypertensive patients in primary health care.

Methods: Randomized controlled clinical trial. The study was conducted within the primary health care, in two units of the Family Health Strategy, covering 11,000 individuals, in Porto Alegre, Brazil. Two hundred and 56 patients, older than 40 years old and with uncontrolled hypertension, systolic blood pressure (BP) $\geq 140 \mathrm{mmHg}$ and/or diastolic BP $\geq 90 \mathrm{mmHg}$ or $\geq 130 \mathrm{mmHg}$ and/or diastolic BP $\geq 80 \mathrm{mmHg}$ for individuals with diabetes. Eligible patients were randomly assigned to a health care program aiming for blood pressure control, with the multidisciplinary program group or with the multidisciplinary program plus personalized care group. Primary outcome measures were reduction in systolic BP from baseline to 6 months. Secondary measures included proportion of patients with systolic or diastolic BP controlled. Student $t$ test, Pearson's chi-squared test, Fisher's exact test, Mann-Whitney $U$ test, Wilcoxon signed-ranks test and generalized estimating equation (GEE) model were used in the analysis.
\end{abstract}

Results: The baseline characteristics of participants were similar between groups. After 6 months of follow-up, systolic BP decreased markedly in both groups $(\triangle-11.8 \mathrm{mmHg}[S D, 20.2]$ in the multidisciplinary program group and $\Delta-12.9 \mathrm{mmHg}[S D, 19.2]$ in the personalized care group; $p<0.001)$. Similarly, we noted a significant change in diastolic BP over time in both groups $(\Delta-8.1 \mathrm{mmHg}[\mathrm{SD}, 10.8]$ in the multidisciplinary program group and $\Delta-7$. $0 \mathrm{mmHg}[\mathrm{SD}, 11.5]$ in the personalized care group; $p<0.001$ ).

Conclusions: The study demonstrates similar effectiveness of a group intervention in comparison to a personalized education program in hypertension patients to achieve BP control. These findings indicate that the intervention can be for all hypertensive patients assisted in primary health care.

(Continued on next page)

\footnotetext{
* Correspondence: reginakuhmmer@gmail.com

${ }^{1}$ Institute for Education and Research, Hospital Moinhos de Vento, Rua

Ramiro Barcelos 910, Bloco D, Porto Alegre, RS 90035-001, Brazil

${ }^{2}$ Graduate Program in Cardiology and Cardiovascular Science, Universidade

Federal do Rio Grande do Sul. National Institute for Health Technology

Assessment - IATS/CNPq, Porto Alegre, Brazil

Full list of author information is available at the end of the article
} 
(Continued from previous page)

Trial registration: ClinicalTrials.gov IdentifierNCT01696318 (May 2013).

Keywords: Hypertension, Public health, Multidisciplinary program, Systolic blood pressure, Diastolic blood pressure, Diabetes Mellitus

Abbreviations: 24 h-DR, 4-h dietary recall; AMl, Acute myocardial infarction; AUDIT, Alcohol use disorders identification test; BARC, Brazilian association of research companies; BMI, Body mass index; BMQ, Brief medication questionnaire; $\mathrm{BP}$, Blood pressure; $\mathrm{CCl}$, Charlson comorbidity index; $\mathrm{Cl}$, Confidence interval; $\mathrm{CVD}$, Cardiovascular disease; CVD, Cardiovascular disease; FBG, Fasting blood glucose; FHS, Family health strategy; FHT, Family health team; FRS, Framingham risk score; GEE, Generalized estimating equation; HbA1c, Glycated hemoglobin; HDI, Human development index; HDL, High-density lipoprotein cholesterol; IPAC, International physical activity questionnaire; IQR, Interval interquartile; LDL, Low-density lipoprotein cholesterol; MFA, Monounsaturated fat acid; PFA, Polyunsaturated fat acid; PHC, Primary health care; SD, Standard deviation; SFA, Saturated fat acid; USA, United States of America; WC, Waist circumference; WHO, World Health Organization; WHR, Waist-to-hip ratio

\section{Background}

Hypertension is a public health problem throughout the world, affecting more than one billion people $[1,2]$. The estimated prevalence in developing countries is $40 \%$, in comparison to $35 \%$ in developed nations [3]. Studies indicate that reductions of $10 \mathrm{mmHg}$ to $12 \mathrm{mmHg}$ in systolic blood pressure (BP) or $5 \mathrm{mmHg}$ to $6 \mathrm{mmHg}$ in diastolic BP, or both, lower the risk of stroke by 35 to $40 \%$, cardiovascular death by 20 to $25 \%$, coronary heart disease by 14 to $16 \%$, and heart failure by $50 \%$ [4-11].

In spite of well-established benefits of low BP, and the existence of several national and international guidelines on diagnostic and management of hypertension, control remains poor [12]. Canada has the lowest prevalence of hypertension at $19 \%$, followed by England and the United States of America (USA) at about $30 \%$ each. However, only $34 \%$ had BP under $140 / 90 \mathrm{mmHg}$ in England, compared with $50 \%$ in the USA and $66 \%$ in Canada [13]. These numbers are even worse in developing countries, where hypertension prevalence is higher. In Brazil, approximately $30 \%$ of adults are hypertensive [14], and BP control rates are even lower, ranging from $57.6 \%$ to around $10 \%[15,16]$.

Health promotion programs related mainly to medication adherence, diet, physical activity and smoking habit have been introduced in different countries for prevention and control of cardiovascular risk factors [17]. Regarding the prevention of cardiovascular disease (CVD) in Brazil, the importance of public policies directed at nutrition and physical activity has been highlighted in the last few years. The National Diet and Nutrition Policy and the adoption of the Global Strategy on Healthy Eating, Physical Exercise and Health, of the World Health Organization (WHO) are examples of public policies, which include recommendations regarding healthy eating as a way to control and prevent CVD in primary health care (PHC) level $[17,18]$.
The Family Health Program and the Support Nucleus for the Family Healthcare (multidisciplinary program) are priority strategies of the Ministry of Health in order to organize PHC in Brazil [19]. It is believed that these strategies are adequate models for addressing CVD by means of prevention and health promotion, aimed to change the behavior and living habits of individuals, without losing sight of the interactions in collective and social spheres [20, 21]. However, no study has evaluated the effects of these programs in chronic disease patients, especially compared with other valid approaches. In this context, the objective of this study was to evaluate the effectiveness of a multidisciplinary program in $\mathrm{PHC}$ to promote BP control in hypertensive patients.

\section{Methods}

\section{Study design and setting}

The study was designed as a randomized, controlled clinical trial. It was conducted in two units under the Family Health Strategy (FHS), in Restinga and ExtremeSouth districts of Porto Alegre, Southern Brazil. These FHS units cover 11,000 individuals and Restinga is a low-income district, with approximately 100,000 people and a Human Development Index (HDI) of 0,700$0,799[22]$.

\section{Participants}

Patients were eligible for inclusion in the study if they were older than 40 years old, with previous hypertension diagnosis, and BP levels above recommended, measured by nurse technicians in screening in the FHS unit. Uncontrolled BP was defined as systolic BP $\geq 140 \mathrm{mmHg}$ and /or diastolic BP $\geq 90 \mathrm{mmHg}$ or $\geq 130 \mathrm{mmHg}$ and /or diastolic $\mathrm{BP} \geq 80 \mathrm{mmHg}$ for individuals with diabetes $[12,23]$. Institutionalized patients, with mental illnesses or disabling chronic illnesses, patients who were exclusively assisted by health insurance and those with a life 
expectancy of less than a year were not included in the study. Also, none of the participants could have been involved in a physical training program or a lifestyle change for 6 months prior to the study.

\section{Screening and recruitment}

All patients who were assisted by a Family Health Team (FHT) with uncontrolled BP from May to July 2013 were invited to participate in the study. Eligible participants were identified through active screening by a research assistant. Three BP measures were performed according to the study protocol, using an appropriately sized cuff and a calibrated automated device with memory for storage of measurements (Omron HEM - 742 INT IntelliSense; Omron Healthcare) in the sitting position, after five minutes of rest, with no less than 1 min between measurements. The average of the second and third measures was used [12, 23].

\section{Interventions}

\section{Health professionals education}

Health care professionals in the FHT (physicians, nurses, social workers) were invited to receive training, aiming to standardized care. The first training, which lasted $90 \mathrm{~min}$, was performed by a cardiologist who focused on standard treatment algorithms for hypertension care and management, which were based on the Seventh Report of the Joint National Committee on Prevention, Detection, Evaluation, and Treatment of High Blood Pressure Guidelines (JNC 7) and the VI Brazilian Guidelines on Hypertension [12, 23].

Another training, which involved all professionals in the FHT, was conducted by a pharmacist, a dietitian and a physical educator who addressed no pharmacologic components (diet, exercise, weight loss, smoking cessation, and other recommendations) and pharmacologic interventions (prescription of drugs provided by the Unified Health System - UHS, and low-cost).

Manuals for health education were designed, based on evidence, for the four main areas of interest: pharmaceutical care (prepared considering the availability of drugs in public pharmacies), nutrition, physical activity, and strategies to be adopted in groups. These manuals were created in order to assist professionals during the study period, and also for the FHT to continue the personalized assistance with patients.

\section{Patients education baseline}

All patients included in the study were invited to participate in educational health workshops, with a dietitian, a physical educator, a pharmacist, and at least one member of the FHT. In these workshops, all participants were oriented to BP control, and received guidance on the benefits of having a healthy life and the deleterious effects of hypertension. The importance of achieving BP targets and adhering to medication was emphasized. After this activity, patients were randomized to the multidisciplinary program in the family healthcare group or multidisciplinary program plus personalized care group.

\section{Multidisciplinary program for the family healthcare group}

Multidisciplinary healthcare teams were established by Ordinance of the Ministry of Health, Decree No. 154 of January 24, 2008, under the name of the Support Nucleus for the Family Healthcare [19]. According to the Ministry, these programs should be performed by teams composed of different health care professionals, to support and to work in partnership with FHT with a focus on health practices in territories under their responsibility. The team who participated in this study consisted of a physical educator, a pharmacist and a dietitian, with the goal to promote adherence to drug treatment, to plan a balanced diet and to encourage the practice of physical activity. The activities offered by the multidisciplinary program were of standard care, and for this study the multidisciplinary program was considered the control group.

The multidisciplinary program group participated in monthly health education instruction and engaged in physical activity twice a week. Health education workshops were conducted in different locations for each of the geographical areas, to facilitate participants' access, in places such as churches, halls, parks, schools and the participants' residence.

The workshops covered topics related to hypertension through lectures and interactive dynamics, using posters, pictures, videos and practical demonstrations (concept, risk factors and treatment); physical activity (benefits and importance of weight reduction or maintenance, as well as improvement in quality of life and daily activities performance, they were also trained to perform the physical activities at home); medication adherence and dietary measures (consumption of fat, sugar and salt, recommendation and dangers of excessive consumption, and incentive to consume fruits and vegetables). Different kinds of fruits and vegetables were taken to the statement of recommended serving size and description of their beneficial health properties was made available. The participants were provided with systematic but flexible guidance, according to the needs and financial conditions of each of them.

A physical educator, in the presence of a pharmacist or a dietitian, and a member of the FHT, conducted a twice-a-week aerobic exercise training. The participants' heart rate and BP were always measured at the beginning and the end of the activity. Each exercise session comprised an initial 5-min warm up, 50-min aerobic 
exercises and a final 5-min cool down phase. The physical activities also had a playful and relaxing profile.

\section{Multidisciplinary program plus personalized care group} In addition to the group activities offered by the multidisciplinary program, the personalized care group (intervention group) also received referral to visit a dietitian and a clinical pharmacist with focus on hypertension control. A dietary approach was planned according to nutritional needs, socioeconomic status, and individual dietary habits. A 24-h dietary recall (24 h-DR) was applied in the 1st, 3rd and 6th month for assessment of dietary habits.

Counseling from the pharmacist included information about proper medication administration, side effects, and disease education. Pharmacists also reviewed patients' medications and prescriptions by completing medication reconciliation; identifying duplicate, unnecessary, or incomplete therapy; checking for drug interactions; verifying patients' formulary drug coverage and medications availability; and ensuring prescription completeness. To minimize variability during the counseling process, a standardized checklist was developed outlining the topics to be covered during a session, and standardized patient education leaflets were used. In order to identify the number of times each drug had to be taken, medication reconciliation was used, which included the names of all the drugs prescribed, with figures corresponding to the moment in which it had to be taken each time. The same illustrative figure was placed in the box of the product.

Patients were encouraged to check BP at home, and an automatic digital arm pressure monitor with memory for storage of measurements (Omron ${ }^{\circ}$, model HEM $742 \mathrm{I})$ was provided twice, during the study period. During the appointment with the pharmacist, patients were trained and instructed to check BP twice a day for five days [24]. For individuals with diabetes, glucometers and test strips (Accu-Check ${ }^{\circ}$ ) for glucose control were provided during the entire study period.

\section{Measurement and data collection}

The primary outcome at 6th month was systolic BP reduction from baseline to the last follow-up visit. The secondary outcome was diastolic BP reduction from baseline to the last follow-up and the proportion of participants with controlled BP, $<140 \mathrm{mmHg}$ for systolic BP or $<90 \mathrm{mmHg}$ for diastolic BP and $<130 \mathrm{mmHg}$ for systolic BP or diastolic BP $<80 \mathrm{mmHg}$ for individuals with diabetes [12].

Other important patient data included demographic (gender, age, race and marital status), socioeconomic (education level and social class, according to the classification of the Brazilian Association of Research
Companies - BARC [25]), and behavioral variables (smoking, alcohol consumption and physical activity). The Alcohol Use Disorders Identification Test (AUDIT) was applied to assess alcohol consumption, and the International Physical Activity Questionnaire (IPAQ) was used to evaluate the level of physical activity [26-28]. Height, weight, waist circumference and hip circumference were measured and the body mass index (BMI) was calculated [29].

The medication adherence was measured using two validated questionnaires in Portuguese: the MoriskyGreen Test with four questions, and the Brief Medication Questionnaire (BMQ) with eleven questions [30-32]. The Charlson Comorbidity Index (CCI) was used to assess the presence of comorbidities. The absolute number for each condition identified was considered [33]. The Biochemical profile was assessed only at the end of the study, and included measurements of total cholesterol, high-density lipoprotein cholesterol (HDL), triglycerides, and lowdensity lipoprotein cholesterol (LDL), fasting blood glucose (FBG) and glycated hemoglobin (HbA1c) levels for individuals with diabetes, all with a 12-h fast. LDL-C was calculated using the Friedewald formula for those with triglycerides levels $<400 \mathrm{mg} / \mathrm{dL}$ [34].

For assessment of global cardiovascular risk we used the Framingham Risk Score (FRS) for nondiabetic individuals and the UKPDS Risk Engine (United Kingdom Prospective Diabetes Study) for individuals with diabetes [35, 36]. According to the FRS, patients were classified as low risk $<10 \%$, intermediate risk $10-20 \%$ and high risk $>20 \%$ probability of cardiovascular event in 10 years.

\section{Randomization}

The randomization sequence was computer-generated and was assigned by a member of the study team who was blind to patient assignment until the intervention. Block randomization was used, with random block sizes of four, six and eight, in order to ensure similar size among the groups. During the study period, patients and health team members were aware of allocated groups. The randomization list was concealed in a central office.

\section{Statistical analysis}

A sample of 127 participants in each trial group (overall of 254 ) was planned, with an $80 \%$ power, and a $p$-value of 0.05 , to detect a reduction of $7.2 \mathrm{mmHg}$ in systolic BP with standard deviation (SD) $20.45 \mathrm{mmHg}$ in the intervention group and SD $20.26 \mathrm{mmHg}$ in the control group [37]. Continuous variables are expressed as mean and SD or median interval interquartile (IQR), and categorical variables are expressed as proportions.

The groups were compared by means of the Student $t$ test for continuous variables, and the Pearson's chisquared test or the Fisher's exact test for categorical 
variables. The Mann-Whitney $U$ test was used in between-group comparisons for variables not normally distributed. The Wilcoxon signed-ranks test for paired samples was used in within-group comparisons. Continuous variables taken at different time intervals were compared by generalized estimating equation model (GEE) to evaluate the effect of group allocation, adjusting for time effect (group * time). The variables were treated as normal distribution, with a connection identity function. The working correlation matrix used was unstructured and robust estimator covariance matrix. For significant effects was used post-hoc Bonferroni. Analysis of variance for linear trend was used to compare the reduction of BP in different levels of physical activity and medication adherence. Control for confounding factors regarding the reduction of $\mathrm{BP}$ levels was performed by multivariate linear regression analysis. For evaluation of medication adherence, the categories of BMQ were grouped into: high adherence and probably high adherence, and probably low adherence and low adherence. $P$ values $<0.05$ were considered statistically significant. All analyses were completed using the Statistical Package for the Social Sciences (version 20.0, SPSS, Chicago, Illinois).

\section{Results}

Patients

The study was conducted from July to December 2013. Among the 280 screened individuals, 256 (91 \%) were considered eligible and were included in the study, 128 were randomly assigned to the multidisciplinary program group, and 128 to the personalized care group (Fig. 1). At the 6th month of the study, 16 patients were excluded from the multidisciplinary program group, due to the following reasons: five lost contact, six of them changed their addresses and three died, and 15 patients were excluded from the personalized care group: seven lost contact, seven changed their addresses and one died. The causes of death were acute myocardial infarction (AMI), stroke and gunshot in the multidisciplinary program group and AMI in the personalized care group.

\section{Baseline characteristics}

Patients in each study group had similar baseline characteristics in respect to age, gender, education, BMI, smoking status, prevalence, baseline blood pressure and presence of chronic illness, with the exception of congestive heart failure history, more frequent in the control group. Most patients in the study ( $84 \%$ for multidisciplinary program

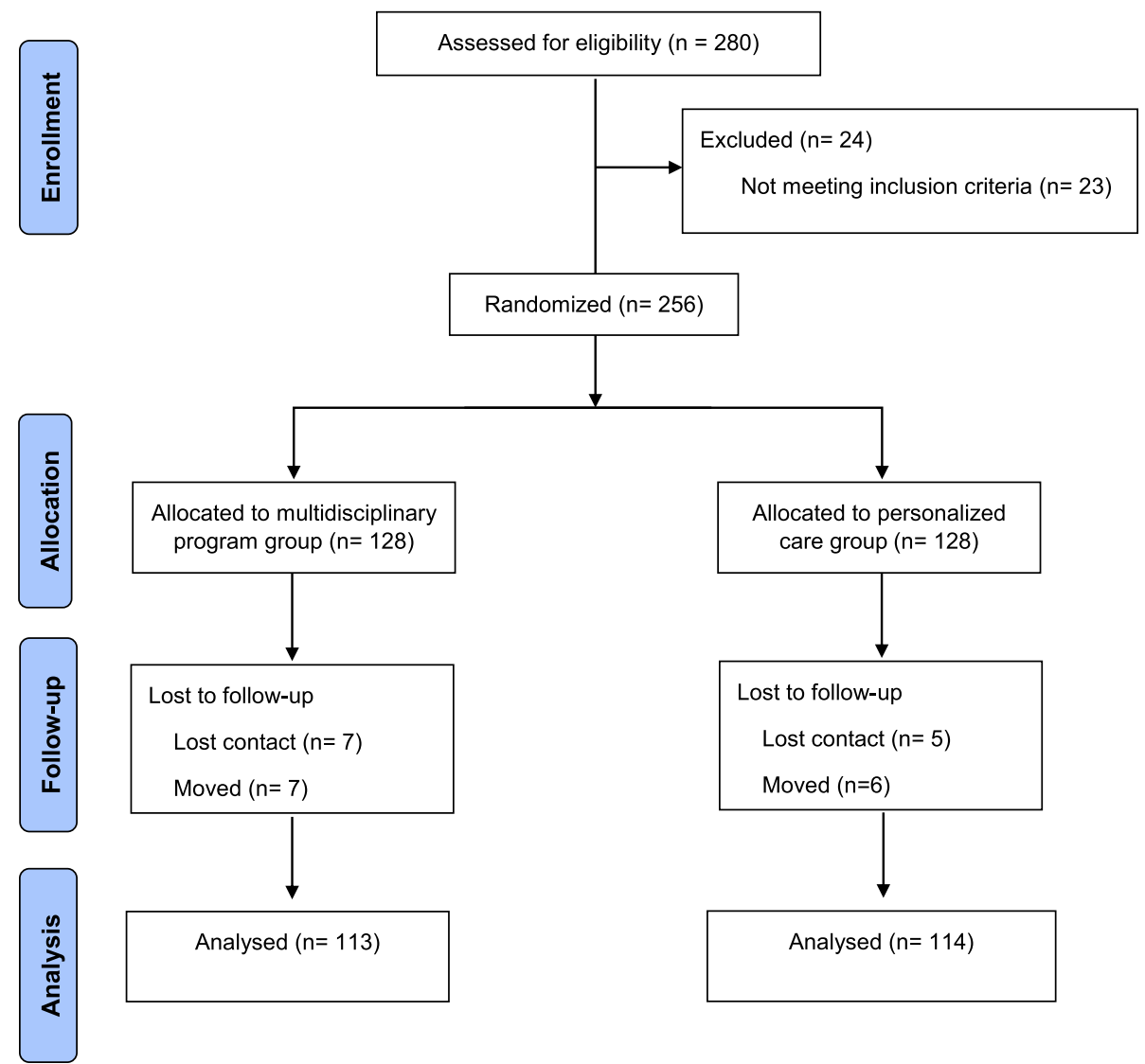

Fig. 1 Study flow diagram 
group and $83 \%$ for personalized care group) had at least score $\geq 1$ comorbidity of the Charlson Index; and $23 \%$ of the patients in the multidisciplinary program group and $27 \%$ in the personalized care group had diabetes (Table 1).

\section{Blood pressure and hypertension control}

During the study period, systolic BP decreased in both treatment groups, $\Delta-11.8 \mathrm{mmHg}(\mathrm{SD}, 20.2)$ in the multidisciplinary program group, $(p<0.001)$ and $\Delta$ $12.9 \mathrm{mmHg}(\mathrm{SD}, 19.2)$ in the personalized care group, $(p<0.001)$, with no significance between the groups, $p=0.60$. Similarly, a significant change in diastolic BP was also noted in respect to time in both groups, $\Delta$ $8.1 \mathrm{mmHg}$ (SD, 10.8) in the multidisciplinary program group $(p<0.001)$ and $\Delta-7.0 \mathrm{mmHg}(\mathrm{SD}, 11.5)$ in the personalized care group $(p<0.001)$, and no significance between groups was observed, $p=0.36$ (Table 2). In the secondary outcome analysis, a significant increase in the proportion of patients with controlled systolic and diastolic BP $(p<0.001)$ was detected, between baseline and 6 -months in both groups (Table 3 ). In addition, the relative risk of not achieving the systolic BP target in individuals with diabetes was 1.64 times higher than in nondiabetics (95\% CI 1.33 to 2.03 ) and 2.87 in diastolic BP (95\% CI 1.87 to 4.41$)$.

\section{Pharmacological treatment and medication adherence}

The pharmacologic treatment during the study was similar for all drug classes. The number of antihypertensive medication prescribed was similar in both groups in the baseline (multidisciplinary program group $83 \%$ vs. personalized care group $83 \%, p=0.74)$, and did not increase significantly over time (multidisciplinary program group $86 \%$ vs. personalized care group $88 \%, p=0.85$ ). Although subjects of both groups were prescribed more antihypertensive drugs, this increase was similar between groups (multidisciplinary program group $p=0.29$ and personalized care group, $p=0.06$ ) (Table 4). Both in the multidisciplinary program group and in the personalized care group there was a percentage of patients without drug prescription, and this condition did not change between and within groups at the end of the study, $p=0.98$. Medication adherence measured by the Morisky-Green Test increased from 34 to $49 \%$ in the multidisciplinary program group and from 35 to $55 \%$ in the personalized care group. In relation to the BMQ test, the medication adherence increased from 35 to $68 \%$ in the multidisciplinary program group and from 22 to $67 \%$ in the personalized care group. There was no significant difference between groups in both tests (Table 5).

\section{Physical activity}

The amount of physical activity performed increased in the multidisciplinary program group and in the personalized care group; $p<0.001$. In addition, the percentage of active people increased from 22 to $49 \%$ in the multidisciplinary program group $(p<0.001)$, and from 21 to $52 \%$ in the personalized care group $(p<0.001)$. However, there was no significant difference between groups. In the linear trend analysis, patients classified as active by IPAC had a greater BP control; systolic BP $(p=0.043)$, diastolic BP $(p=0.039)$, but when adjusted for gender and medication adherence, only medication adherence remained significant $(p=0.027)$.

\section{Anthropometric measures, biochemical profile and cardiovascular risk}

Regarding anthropometric measures, no differences were observed between the groups in variables such as BMI, waist circumference (WC) and waist-to-hip ratio (WHR) within 6 months (Table 2). BP self-monitoring in both groups increased over time, $p=0.001$, but there was no difference between groups, $p=0.473$ (Table 4). The results of biochemical profile and of cardiovascular risk are shown on Table 6. Biochemical tests were not available for most patients at baseline; therefore, only 6-month values are presented. The groups did not significantly differ at the end of the study, regarding biochemical profile and cardiovascular risk, both in individuals with and without diabetes (Table 6). The percentage of smoking and alcohol consumption decreased in both groups, but it was not of significance (data not shown).

\section{Dietary assessment}

There were no statistically significant differences in total calories intake, macronutrients (carbohydrate, protein and total lipids), saturated fat acid (SFA), polyunsaturated fat acid (PFA) and monounsaturated fat acid (MFA) between groups after the intervention. Similarly, cholesterol, micronutrients (calcium, iron and potassium), fibers and sodium did not differ significantly. Regarding fruit ingestion, there was a significant higher consumption in the personalized care group (data not shown).

\section{Discussion}

In this study we evaluated the effectiveness of a multidisciplinary program, suggested by the Ministry of Health, to promote BP control in hypertensive patients in PHC, in Brazil. The results of this study show that among adults with uncontrolled BP, an education strategy with multidisciplinary program alone or combined with personalized care in BP management reduced systolic and diastolic BP significantly and increased the proportion of patients with BP on target.

Our educational program resulted in $11.8 \mathrm{mmHg}$ and $12.9 \mathrm{mmHg}$ reductions in systolic BP in both multidisciplinary program group and personalized care groups, 
Table 1 Sociodemographic, clinical and behavioral characteristics of participants

\begin{tabular}{|c|c|c|c|}
\hline \multirow[t]{3}{*}{ Characteristic } & \multicolumn{3}{|l|}{ Group } \\
\hline & \multirow{2}{*}{$\begin{array}{l}\text { Multidisciplinary Program } \\
n=128\end{array}$} & \multirow{2}{*}{$\begin{array}{l}\text { Personalized Care } \\
n=128\end{array}$} & \multirow[t]{2}{*}{$p$-value } \\
\hline & & & \\
\hline Gender, male & $40(31)$ & $35(27)$ & $0.583^{\mathrm{a}}$ \\
\hline Age, years & $60 \pm 11$ & $59 \pm 10$ & $0.527^{b}$ \\
\hline \multicolumn{4}{|l|}{ Race } \\
\hline White & $98(77)$ & $95(74)$ & \multirow[t]{3}{*}{$0.652^{a}$} \\
\hline Yellow & $17(13)$ & $22(17)$ & \\
\hline Black & $13(10)$ & $11(9)$ & \\
\hline \multicolumn{4}{|l|}{ Years of education completed } \\
\hline $0-4$ & $62(48)$ & $59(46)$ & \multirow[t]{3}{*}{$0.410^{\mathrm{a}}$} \\
\hline $5-8$ & $41(32)$ & $50(39)$ & \\
\hline$\geq 9$ & $25(20)$ & $19(15)$ & \\
\hline \multicolumn{4}{|l|}{ Marital status } \\
\hline Married & $74(58)$ & $78(61)$ & \multirow[t]{4}{*}{$0.364^{a}$} \\
\hline Single & $14(11)$ & $8(6)$ & \\
\hline Separated & $13(10)$ & $19(15)$ & \\
\hline Widowed & $27(21)$ & $23(18)$ & \\
\hline \multicolumn{4}{|l|}{ Social class, BARC } \\
\hline High, A/B & $37(29)$ & $33(26)$ & \multirow[t]{3}{*}{$0.277^{\mathrm{a}}$} \\
\hline Medium, C & $62(48)$ & $74(58)$ & \\
\hline Low, D/E & $29(23)$ & $21(16)$ & \\
\hline $\mathrm{BMI}, \mathrm{Kg} / \mathrm{m}^{2}$ & $30 \pm 0.5$ & $30 \pm 0.5$ & $0.784^{b}$ \\
\hline \multicolumn{4}{|l|}{ Blood pressure, $\mathrm{mmHg}$} \\
\hline Systolic & $156 \pm 2$ & $158 \pm 2$ & $0.437^{b}$ \\
\hline Diastolic & $89 \pm 1$ & $90 \pm 1$ & $0.633^{b}$ \\
\hline \multicolumn{4}{|l|}{ Comorbidity Index } \\
\hline $\mathrm{CCl}$ & $2(1-3)$ & $2(1-4)$ & $0.704^{c}$ \\
\hline $\mathrm{CCl}-\mathrm{Y}$ & $4(2-5)$ & $3(2-5)$ & $0.951^{c}$ \\
\hline CIC-Y, survival 10 years & $53(11-85)$ & $56(16-82)$ & $0.843^{c}$ \\
\hline \multicolumn{4}{|l|}{ Comorbidity } \\
\hline Previous myocardial infarction & $16(13)$ & $10(8)$ & $0.214^{a}$ \\
\hline Heart failure & $22(17)$ & $11(9)$ & $0.040^{\mathrm{a}}$ \\
\hline Peripheral vascular disease & $13(10)$ & $13(10)$ & $1.000^{\mathrm{a}}$ \\
\hline Stroke & $18(14)$ & $17(13)$ & $0.856^{\mathrm{a}}$ \\
\hline Diabetes Mellitus & $32(23)$ & $34(27)$ & $0.564^{\mathrm{a}}$ \\
\hline COPD & $9(7)$ & $5(4)$ & $0.272^{a}$ \\
\hline Connective tissue disease & $57(45)$ & $69(54)$ & $0.134^{\mathrm{a}}$ \\
\hline Gastric ulcers & $24(19)$ & $24(19)$ & $1.000^{\mathrm{a}}$ \\
\hline Liver disease & $12(9)$ & $13(10)$ & $1.000^{\mathrm{a}}$ \\
\hline Renal disease & $17(13)$ & $20(16)$ & $0.594^{\mathrm{a}}$ \\
\hline
\end{tabular}


Table 1 Sociodemographic, clinical and behavioral characteristics of participants (Continued)

\begin{tabular}{llll}
\hline Cancer & $10(8)$ & $5(4)$ & \\
Smoking status & & $52(47)$ \\
Never & $50(43)$ & $20(18)$ \\
Current & $25(21)$ & $38(35)$ \\
Past & $42(36)$ & $0.563^{\mathrm{a}}$ \\
\hline
\end{tabular}

BARC Brazilian association of research companies, BMI Body mass index, CCI Charlson comorbidity index, CCI-Y Charlson comorbidity-year index, COPD Chronic obstructive pulmonary disease. Values expressed $\mathrm{n}(\%)$, mean and standard error (SE) or median and interquartile range (IQR)

aPerson chi-square test or Fisher's exact test

${ }^{\mathrm{b}}$ Student's $t$-test

${ }^{c}$ Mann-Whitney $U$ test

Table 2 Blood pressure and clinical measurements from baseline to end of study

\begin{tabular}{|c|c|c|c|c|c|}
\hline \multirow[t]{3}{*}{ Variable } & \multicolumn{2}{|l|}{ Group } & \multicolumn{3}{|l|}{$p$-value } \\
\hline & Multidisciplinary Program & Personalized Care & Group & Time & Interaction \\
\hline & $n=113$ & $n=114$ & & & \\
\hline \multicolumn{6}{|c|}{ Systolic BP, mmHg } \\
\hline Baseline & $156 \pm 1.6(128)$ & $158 \pm 1.8(128)$ & 0.575 & $<0.001$ & 0.600 \\
\hline 6 Months & $144 \pm 1.8(114)$ & $143 \pm 1.8(113)$ & & & \\
\hline$\Delta$ & $-11.8 \pm 20.2$ & $-12.9 \pm 19.2$ & & & \\
\hline \multicolumn{6}{|c|}{ Diastolic BP, mmHg } \\
\hline Baseline & $89 \pm 1.02(128)$ & $90 \pm 1.03(128)$ & 0.286 & $<0.001$ & 0.365 \\
\hline 6 Months & $80 \pm 1.03(114)$ & $82 \pm 1.09(113)$ & & & \\
\hline$\Delta$ & $-8.10 \pm 10.8$ & $-7.0 \pm 11.5$ & & & \\
\hline \multicolumn{6}{|l|}{$\mathrm{BMI}, \mathrm{Kg} / \mathrm{m}^{2}$} \\
\hline Baseline & $29.9 \pm 0.5(128)$ & $30.1 \pm 0.5(128)$ & 0.745 & 0.454 & 0.859 \\
\hline 6 Months & $30 \pm 0.5(114)$ & $30.2 \pm 0.5(113)$ & & & \\
\hline$\Delta$ & $0.08 \pm 1.9$ & $0.13 \pm 2.9$ & & & \\
\hline \multicolumn{6}{|l|}{$W C, c m$} \\
\hline Baseline & $95.1 \pm 1.7(127)$ & $96.1 \pm 1.2(126)$ & 0.438 & 0.122 & 0.608 \\
\hline 6 Months & $95.6 \pm 1(113)$ & $96.9 \pm 1.1(113)$ & & & \\
\hline$\Delta$ & $0.40 \pm 5.9$ & $0.82 \pm 6.6$ & & & \\
\hline \multicolumn{6}{|l|}{ WHR } \\
\hline Baseline & $0.91 \pm 0(127)$ & $0.92 \pm 0(126)$ & 0.482 & 0.098 & 0.482 \\
\hline 6 Months & $0.90 \pm 0(113)$ & $0.91 \pm 0(113)$ & & & \\
\hline$\Delta$ & $-0.012 \pm 0.06$ & $-0.003 \pm 0.88$ & & & \\
\hline \multicolumn{6}{|c|}{ Appointments, number } \\
\hline Baseline & $3.82 \pm 0.4$ & $2.95 \pm 0.2$ & 0.258 & $<0.001$ & 0.084 \\
\hline 6 Months & $1.9 \pm 0.2$ & $2.02 \pm 0.2$ & & & \\
\hline$\triangle$ & $-1.94 \pm 0.4$ & $-0.93 \pm 0.3$ & & & \\
\hline \multicolumn{6}{|c|}{ Physical activity, min per week } \\
\hline Baseline & $87 \pm 12$ & $96 \pm 14$ & 0.114 & $<0.001$ & 0.110 \\
\hline 6 Months & $188 \pm 17$ & $245 \pm 27$ & & & \\
\hline$\Delta$ & $103 \pm 15$ & $151 \pm 26$ & & & \\
\hline
\end{tabular}

BP Blood pressure, BMI Body mass index, WC Waist circumference, WHR Waist-to-hip ratio. Values expressed $\mathrm{n}(\%)$, mean and standard error (SE), GEE Generalized estimating equationan overview of five randomized controlled 
Table 3 Blood pressure control from baseline to end of study

\begin{tabular}{|c|c|c|c|c|c|c|c|c|}
\hline \multirow[t]{4}{*}{ Variables } & \multicolumn{8}{|l|}{ Group } \\
\hline & \multicolumn{3}{|c|}{ Multidisciplinary Program } & \multicolumn{3}{|c|}{ Personalized Care } & \multicolumn{2}{|c|}{ Between group } \\
\hline & Baseline & 6 Months & $p$-value & Baseline & 6 Months & $p$-value & Baseline & 6 Months \\
\hline & $n=128$ & $n=113$ & & $n=128$ & $n=114$ & & $p$-value & \\
\hline \multicolumn{9}{|l|}{ Systolic BP } \\
\hline Nondiabetic & $7(9)$ & $40(49)$ & $<0.001$ & $5(7)$ & $44(57)$ & $<0.001$ & 0.451 & 0.744 \\
\hline Diabetic & $0(0)$ & $9(27)$ & 0.003 & $0(0)$ & $8(22)$ & 0.014 & & \\
\hline \multicolumn{9}{|l|}{ Diastolic BP } \\
\hline Nondiabetic & $37(47)$ & $68(86)$ & $<0.001$ & $36(47)$ & $62(81)$ & $<0.001$ & 0.697 & 0.473 \\
\hline Diabetic & $6(18)$ & $17(52)$ & 0.003 & $5(14)$ & $19(53)$ & $<0.001$ & & \\
\hline
\end{tabular}

$B P$ blood pressure. BP control defined as systolic BP $<140$ or diastolic BP $90 \mathrm{mmHg}$ for nondiabetic patients and systolic BP level $<130 \mathrm{mmHg}$ or diastolic $\mathrm{BP}<80 \mathrm{mmHg}$ for diabetic patients. Values expressed $\mathrm{n}(\%)$. Person chi-square test

respectively. For nondiabetic individuals, rates of systolic BP under control were of 8.6 to $49.4 \%$ in the multidisciplinary program group and of 6.6 to $57.1 \%$ in the personalized care group. In individuals with diabetes, the systolic BP control was of 0 to $27 \%$ in the multidisciplinary program group and of 0 to $22.2 \%$ in the personalized care group. Our control rate was lower in individuals with diabetes than in nondiabetic individuals; however, literature data indicate that the rate control in these individuals could be as low as $3 \%$, similar to findings at the beginning of this study [38].

A systematic review of 24 observational studies including 47,964 individuals, with both hypertension and diabetes, reported that only $12 \%$ (range 6 to $30 \%$ ) of participants had controlled BP [39].
Our study showed significant BP reductions in both groups without alterations on medications prescribed. There are some potential explanations for the good BP results, including BP goal reinforcement by the education program, medication adherence and lifestyle modifications, as well as regular physical activity practice. Increased adherence to medications probably played an important role in the results observed. In the study of Guiraro et al. [40], the treatment adherence measured by the Morisky-Green Test increased by $9.6 \%$ in the intervention group and $8.8 \%$ in the control group. The intervention consisted of personalized information by a trained nurse and written leaflets and the individuals allocated to the control group received the usual clinical care without any standardized intervention. In our study,

Table 4 Pharmacologic treatment

\begin{tabular}{|c|c|c|c|c|c|c|c|c|}
\hline \multirow[t]{3}{*}{ Variable } & \multicolumn{3}{|c|}{ Multidisciplinary Program } & \multicolumn{3}{|c|}{ Personalized Care } & \multicolumn{2}{|c|}{ Between groups } \\
\hline & Baseline & 6 Months & $\overline{p \text {-value }}$ & Baseline & 6 Months & $\overline{p \text {-value }}$ & Baseline & 6 Months \\
\hline & $n=128$ & $n=113$ & & $n=128$ & $n=114$ & & $p$-value & \\
\hline \multicolumn{9}{|l|}{ Medication class } \\
\hline Not prescription & $5(4)$ & 9 (8) & 0.289 & $13(12)$ & $10(8)$ & 0.453 & 0.084 & 0.984 \\
\hline Antihypertensives & $94(83)$ & $98(86)$ & 0.289 & $94(83)$ & $99(88)$ & 0.063 & 0.743 & 0.845 \\
\hline Antidiabetic & $29(26)$ & $30(27)$ & 1.000 & $31(28)$ & $34(31)$ & 0.508 & 0.388 & 0.558 \\
\hline Antidepressive agents & $27(24)$ & $25(22)$ & 0.880 & $34(30)$ & $29(26)$ & 0.533 & 0.322 & 0.536 \\
\hline Other cardiovascular drugs & $36(32)$ & $40(35)$ & 0.481 & $45(40)$ & $5(40)$ & 1.000 & 0.090 & 0.095 \\
\hline Pulmonary & $5(5)$ & $6(5)$ & 1.000 & $6(6)$ & $7(6)$ & 1.000 & 0.769 & 0.784 \\
\hline Hypolipidemic agents & $36(32)$ & $40(35)$ & 0.503 & $39(35)$ & $41(37)$ & 0.774 & 0.687 & 0.890 \\
\hline \multicolumn{9}{|l|}{ Antihypertensive drugs } \\
\hline Diuretics & $49(44)$ & $55(49)$ & 0.286 & $49(44)$ & $59(53)$ & 0.052 & 1.000 & 0.592 \\
\hline Beta blockers & $31(27)$ & $38(34)$ & 0.118 & $35(32)$ & $39(36)$ & 0.424 & 0.342 & 1.000 \\
\hline ACE & $66(58)$ & $66(58)$ & 1.000 & $63(57)$ & $63(57)$ & 1.000 & 0.704 & 0.789 \\
\hline ARBs & $10(9)$ & $13(12)$ & 0.508 & $17(16)$ & $23(21)$ & 0.70 & 0.079 & 0.150 \\
\hline CCB & $19(17)$ & $22(20)$ & 0.453 & $15(14)$ & $21(19)$ & 0.146 & 0.486 & 0.867 \\
\hline
\end{tabular}


Table 5 Behavioral and medication adherence

\begin{tabular}{|c|c|c|c|c|c|c|c|c|}
\hline \multirow[t]{4}{*}{ Variable } & \multicolumn{8}{|l|}{ Group } \\
\hline & \multicolumn{3}{|c|}{ Multidisciplinary Program } & \multicolumn{3}{|c|}{ Personalized Care } & \multicolumn{2}{|c|}{ Between groups } \\
\hline & Baseline & 6 Months & $\overline{p \text {-value }}$ & Baseline & 6 Months & $p$-value & Baseline & 6 Months \\
\hline & $n=128$ & $n=113$ & & $n=128$ & $n=114$ & & $p$-value & \\
\hline \multicolumn{9}{|l|}{$\overline{\text { IPAC }}$} \\
\hline Active & $25(22)$ & $56(49)$ & 0.001 & $24(21)$ & $59(52)$ & $<0.001$ & 0.930 & 0.750 \\
\hline Insufficient active & $39(34)$ & $40(35)$ & & $41(36)$ & $40(35)$ & & & \\
\hline Inactive & $50(44)$ & $18(16)$ & & $48(43)$ & $14(12)$ & & & \\
\hline \multicolumn{9}{|l|}{ Considers health } \\
\hline Very bad & $7(6)$ & $7(6)$ & 0.133 & $8(7)$ & $2(2)$ & 0.047 & 0.701 & 0.253 \\
\hline Bad & $13(11)$ & $13(11)$ & & $14(12)$ & $8(7)$ & & & \\
\hline Regular & $55(48)$ & $44(39)$ & & $46(41)$ & $42(37)$ & & & \\
\hline Good & $38(33)$ & $45(40)$ & & $42(37)$ & $53(47)$ & & & \\
\hline Very Good & $1(1)$ & $5(4)$ & & $3(3)$ & $8(7)$ & & & \\
\hline \multicolumn{9}{|l|}{ BP self-monitoring } \\
\hline Every day & $16(14)$ & $28(25)$ & $<0.001$ & $13(12)$ & $21(19)$ & $<0.001$ & 0.532 & 0.473 \\
\hline Once week & $28(25)$ & $29(25)$ & & $22(20)$ & $38(34)$ & & & \\
\hline Once month & $19(17)$ & $42(37)$ & & $20(18)$ & $36(32)$ & & & \\
\hline Rarely & $49(43)$ & $13(11)$ & & $57(50)$ & $17(15)$ & & & \\
\hline Never & $2(1.8)$ & $2(2)$ & & $1(1)$ & $1(1)$ & & & \\
\hline \multicolumn{9}{|l|}{ BMQ } \\
\hline High adherence & $35(35)$ & $69(68)$ & $<0.001$ & $21(22)$ & $64(67)$ & $<0.001$ & 0.093 & 0.996 \\
\hline Low adherence & $66(65)$ & $32(32)$ & & $75(78)$ & $32(33)$ & & & \\
\hline \multicolumn{9}{|l|}{ TMG } \\
\hline Adherence & $34(34)$ & $49(49)$ & 0.008 & $34(35)$ & $53(55)$ & $<0.001$ & 0.635 & 0.810 \\
\hline Moderate Adherent & $55(55)$ & $47(47)$ & & $44(46)$ & $39(41)$ & & & \\
\hline Low adherence & $12(12)$ & $5(5)$ & & $18(19)$ & $4(4)$ & & & \\
\hline Improved self-esteem & & $90(79)$ & & & $102(90)$ & & & $<0.001$ \\
\hline
\end{tabular}

IPAC International Physical Activity Questionnaire, BP blood pressure, BMQ Brief Medication Questionnaire, TMG Test Morisky-Green, AUDIT Alcohol Use Disorder Identification Test. Values are $\mathrm{n}(\%)$. Person chi-square test

there was a $15 \%$ increase in the multidisciplinary program group and $20 \%$ in the personalized care group.

Healthy life style, especially engagement in physical activities was highly emphasized, and also could have had some effect on BP control. The protocol required that both groups practiced physical activity twice a week and participated in health education workshops once a month. It was demonstrated in a prior study that more participants in the exercise group $(56.7 \%)$ than in the control group (35.5\%) attained adequate BP control (<140/90 mmHg) post-12-week interventions [41].

Although prior trials suggested that empowerment, constant feedback and individualized care are more effective in achieving medication and care adherence, in our study the combination of these elements in the personalized care did not translate into greater BP control than in the multidisciplinary program. This result suggests that the activities conducted in groups can be as effective as individual guidelines, if performed accordingly.

No reductions were observed in anthropometric measurements in our study. Similarly, in a cluster randomized controlled trial, Harris MF et al. [42], found a small weight reduction $(1.06 \mathrm{~kg})$ that was achieved only among those attending the intervention group, participating in the education program. Improved glycemic control reduced microvascular and macrovascular complications associated with type 2 diabetes mellitus. At the 6th month, we found an average of $6.6 \mathrm{mg} / \mathrm{dL}$ in the multidisciplinary program group and $6.4 \mathrm{mg} / \mathrm{dL}$ in the personalized care group, in HbA1c. However, the lack of baseline data precludes any conclusion regarding diabetes control in our population.

Self-care activities which help to control blood glucose levels and to avoid diabetes-related complications are important in diabetes treatment. Doucette et al. [43] 
Table 6 Cardiovascular risk factors at the end of the study

\begin{tabular}{|c|c|c|c|}
\hline \multirow[t]{3}{*}{ Variable } & \multicolumn{3}{|l|}{ Group } \\
\hline & Multidisciplinary Program & Personalized Care & $p$-value \\
\hline & $n=113$ & $n=114$ & \\
\hline \multicolumn{4}{|l|}{$\mathrm{FBG}, \mathrm{mg} / \mathrm{dL}$} \\
\hline Diabetic & $137 \pm 52(32)$ & $135 \pm 36$ & $0.905^{\mathrm{a}}$ \\
\hline Nondiabetic & $92 \pm 16(68)$ & $93 \pm 15(67)$ & $0.712^{\mathrm{a}}$ \\
\hline $\mathrm{HbA} 1 \mathrm{c}, \%$ & $6.6 \pm 2(32)$ & $6.4 \pm 1$ (33) & $0.634^{\mathrm{a}}$ \\
\hline Total cholesterol, mg/dL & $191 \pm 47(107)$ & $198 \pm 47(104)$ & $0.263^{\mathrm{a}}$ \\
\hline $\mathrm{HDL}, \mathrm{mg} / \mathrm{dL}$ & $45 \pm 12(107)$ & $45 \pm 12(104)$ & $0.916^{\mathrm{a}}$ \\
\hline $\mathrm{LDL}, \mathrm{mg} / \mathrm{dL}$ & $113 \pm 41(96)$ & $119 \pm 41(98)$ & $0.297^{\mathrm{a}}$ \\
\hline Triglyceride, mg/dL & $143(113-190)(107)$ & $143(112-213)(104)$ & $0.769^{b}$ \\
\hline \multicolumn{4}{|c|}{ Nondiabetic, 10 years FRS, n\% } \\
\hline Low & $47(63)$ & $39(55)$ & $0.528^{c}$ \\
\hline Medium & $19(25)$ & $24(34)$ & \\
\hline High & $9(12)$ & $8(11)$ & \\
\hline Mean FRS & $5(2-14)$ & $6(3-14)$ & $0.647^{b}$ \\
\hline \multicolumn{4}{|c|}{ Diabetic, UKPDS, risk 10 year, \% } \\
\hline $\mathrm{CHD}$ & $12(8-17)(32)$ & $11(6-19)$ & $0.572^{b}$ \\
\hline Fatal CHD & $7(4-10)(32)$ & $6(3-13)$ & $0.682^{b}$ \\
\hline Stroke & $7(5-12)(32)$ & $5.5(3-12)$ & $0.993^{b}$ \\
\hline Fatal Stroke & $1(1-2)(32)$ & $1(1-2)$ & $0.992^{b}$ \\
\hline
\end{tabular}

observed, in a randomized clinical trial, that a pharmacistprovided diabetes care service led to significant improvement in self-management and self-care activities in individuals with diabetes. A main challenge for our study was to motivate individuals to participate in the activities proposed. Rates of attendance and completion of lifestyle programs are often poor and highly variable in general practice [44].

This study was unable to determine the variables that influenced the reduction of BP. However, it was designed to assess the effect of an education program to promote $\mathrm{BP}$ control in hypertensive individuals in $\mathrm{PHC}$, not to determine the mechanisms by which a reduction in BP was achieved. It is believed that the benefit of an education program on lowering BP was due to a combination of strategies and not one isolated element, such as changes in lifestyle, physical activity and greater medication adherence [45].

Some caveats of this study ought to be considered. Firstly, variance in BP could have occurred because observations within groups may have correlated, that is, both groups were composed of people who visited the same places, lived in the same neighborhood or nearby, or may be more similar than those in different locations.
Secondly, the values of biochemical tests were not available at baseline, and it was believed that these patients should have had several of these examinations in their routine, but they were not available. Moreover, the $24 \mathrm{~h}-\mathrm{DR}$ was not performed at baseline in the multidisciplinary program group, only at the 6th months. This fact limits comparisons of groups at baseline and at 6 months and it cannot be stated that dietary data changed during the period.

\section{Conclusions}

The study demonstrates the effectiveness of a multidisciplinary program intervention in $\mathrm{BP}$ control in the setting of primary care. The combination of personalized care, involving nutritionists and clinical pharmacists, did not translate into additional benefit of achieving BP control. These findings indicate that the model proposed for the Family Health Program by the Support Nucleus for the Family Healthcare (multidisciplinary program) must be considered for all hypertensive patients assisted in PHC. Other studies with longer period of follow up should be conducted to evaluate the impact of these interventions on clinical outcomes associated with biochemical profile and cardiovascular risk. 


\section{Acknowledgements}

None.

\section{Funding}

This study was supported by the Institutional Development Program of the Brazilian National Health System (PROADI-SUS). Project developed by the Technical Operation and Management of Health Services in an interdistrict Region of Porto Alegre, RS - Restinga Districts and extreme south, adjustment term number 05/2011, signed by the Ministry of Health with Hospital Moinhos de Vento, on 30 December 2011. Sponsored by Institute of Health Technology Assessment (IATS/ CNPq). Public notice No. 69/2010, research team: Management models that qualify with the primary impact on improving indicators of cardiovascular risk (Project 564829/2010-2).

\section{Availability of data and materials}

The datasets during and/or analysed during the current study available from the corresponding author on reasonable request.

\section{Authors' contributions}

CAP and GANB conceived the study. RK, CAP, GANB, FVR and SC participated in the study design. SA and IF included and collected clinical data of the patients. RK, CAP, GANB and SC developed the study intervention. CMG, LARL and TSD delivered the proposed intervention. RK, RKL and CAP were responsible for data management and analysis. RKN was the study coordinator and CAP is the principal investigator. RK, RKL, FVR and CAP wrote the manuscript. All authors reviewed and approved the final manuscript.

\section{Consent to publication}

Not applicable.

\section{Competing interests}

The authors declared no potential conflicts of interest with respect to the research, authorship, and/or publication of this study.

\section{Ethical approval and consent to participate}

This study has been approved by the Institutional Review Board of Hospital Moinhos de Vento of Porto Alegre (approval number 2011/87) and by the Institutional Review Board of Municipal Health of Porto Alegre (approval number 001.037798.11.1). Written informed consent was obtained from each participant at the time of enrolment. The trial has been registered in the Clinical Trial Registry NCT01696318 and in the Brazilian Registry of Clinical Trials U1111-1134-6977, and is in accordance with the Brazilian Ethics in Human Research Regulations.

\section{Author details}

'Institute for Education and Research, Hospital Moinhos de Vento, Rua Ramiro Barcelos 910, Bloco D, Porto Alegre, RS 90035-001, Brazil. ' $G$ raduate Program in Cardiology and Cardiovascular Science, Universidade Federal do Rio Grande do Sul. National Institute for Health Technology Assessment IATS/CNPq, Porto Alegre, Brazil. ${ }^{3}$ Department of Public Health, Universidade Federal de Ciências da Saúde de Porto Alegre, Porto Alegre, Brazil.

\section{Received: 12 December 2015 Accepted: 24 August 2016} Published online: 31 August 2016

\section{References}

1. Committee ESoH-ESoCG. European Society of Hypertension-European Society of Cardiology guidelines for the management of arterial hypertension. J Hypertens. 2003;21(6):1011-53.

2. World Health Organization. World Health Report 2002-Reducing Risks, Promoting Healthy Life. Geneva: World Health Organization; 2002. http://www.who.int/whr/2002/. Accessed 24 Aug 2016.

3. World Health Organization. Global status report on noncommunicable diseases 2010. Geneva: World Health Organization; 2011.

4. MacMahon S, Rodgers A. The effects of blood pressure reduction in older patients: an overview of five randomized controlled trials in elderly hypertensives. Clin Exp Hypertens. 1993;15(6):967-78.

5. Ogden LG, He J, Lydick E, Whelton PK. Long-term absolute benefit of lowering blood pressure in hypertensive patients according to the JNC VI risk stratification. Hypertension. 2000;35(2):539-43.
6. Neal B, MacMahon S, Chapman N, Collaboration BPLTT. Effects of ACE inhibitors, calcium antagonists, and other blood-pressure-lowering drugs: results of prospectively designed overviews of randomised trials. Blood Pressure Lowering Treatment Trialists' Collaboration. Lancet. 2000; 356(9246):1955-64.

7. Benetos A, Thomas F, Safar ME, Bean KE, Guize L. Should diastolic and systolic blood pressure be considered for cardiovascular risk evaluation: a study in middle-aged men and women. J Am Coll Cardiol. 2001;37(1):163-8.

8. Benetos A, Thomas F, Bean K, Gautier S, Smulyan H, Guize L. Prognostic value of systolic and diastolic blood pressure in treated hypertensive men. Arch Intern Med. 2002;162(5):577-81.

9. Pastor-Barriuso R, Banegas JR, Damián J, Appel $\amalg$, Guallar E. Systolic blood pressure, diastolic blood pressure, and pulse pressure: an evaluation of their joint effect on mortality. Ann Intern Med. 2003;139(9):731-9.

10. Onat A, Ceyhan K, Erer B, Başar O, Uysal O, Sansoy V. Systolic, diastolic, and pulse pressures as coronary risk factors in a population with low cholesterol levels: a prospective 10-year evaluation. Clin Cardiol. 2003;26(2):91-7.

11. Roumie CL, Elasy TA, Greevy R, Griffin MR, Liu X, Stone WJ, Wallston KA, Dittus RS, Alvarez V, Cobb J, et al. Improving blood pressure control through provider education, provider alerts, and patient education: a cluster randomized trial. Ann Intern Med. 2006;145(3):165-75.

12. James PA, Oparil S, Carter BL, Cushman WC, Dennison-Himmelfarb C, Handler J, Lackland DT, LeFevre ML, MacKenzie TD, Ogedegbe O, et al. Evidence-Based Guideline for the Management of High Blood Pressure in Adults Report From the Panel Members Appointed to the Eighth Joint National Committee (JNC 8). JAMA. 2014;311(5):507-20.

13. Joffres M, Falaschetti E, Gillespie C, Robitaille C, Loustalot F, Poulter N, McAlister FA, Johansen H, Baclic O, Campbell N. Hypertension prevalence, awareness, treatment and control in national surveys from England, the USA and Canada, and correlation with stroke and ischaemic heart disease mortality: a cross-sectional study. BMJ Open. 2013;3:e003423.

14. Picon RV, Fuchs FD, Moreira LB, Riegel G, Fuchs SC. Trends in prevalence of hypertension in Brazil: a systematic review with meta-analysis. PLoS One. 2012;7(10):e48255.

15. Pinho NA, Pierin AMG. Hypertension Control in Brazilian Publications. Arq Bras Cardiol. 2013:101(3):e65-7.

16. Nogueira D, Faerstein E, Coeli CM, Chor D, Lopes CS, Werneck GL. Awareness, treatment and control of arterial hypertension: Pro-Saude Study. Brazil Rev Panam Salud Publica. 2010;27(2):103-9.

17. World Health Organization. Global action plan for the prevention and control of NCDs 2013-2020. WHO; 2013. www.who.int/nmh/events/ncd_ action_plan/en/. Accessed 24 Aug 2016.

18. Ministry of Health. Department of Health Care. Department of Primary Care. General Coordination of Food and Nutrition Policy. Food Guide of the Brazilian Population: Promoting healthy eating. Brazil: Brasilia: Ministry of Health; 2005.

19. Ministry of Health. Ordinance No. 154 / GM of 24 January 2008. It provides for the creation of Nucleus of Support to Family Health Teams. Brazil: Brasilia: Ministry of Health; 2008.

20. Starfield B, Shi L, Macinko J. Contribution of primary care to health systems and health. Milbank Q. 2005;83(3):457-502.

21. Blasco PG, Levites MR, Janaudis MA, Moreto G, Roncoletta AF, de Benedetto MA, Pinheiro TR. Family medicine education in Brazil: challenges, opportunities, and innovations. Acad Med. 2008;83(7):684-90.

22. Atlas of human development in the metropolitan region of Porto Alegre. Porto Alegre: City Hall /Secretariat for Political Coordination and Local Governance. Metroplan; PNUD; Foundation João Pinheiro, 2008, 32. Available in: http://www.atlasbrasil.org.br/2013/en/perfil_m/porto-alegre_rs. Accessed 24 Aug 2016.

23. Brazilian Society of Cardiology, Brazilian society of hypertension, Brazilian Society of Nephrology. VI Brazilian Guidelines on Hypertension. Arq Bras Cardiol. 2010;95(1 Suppl):1-51.

24. Brazilian Society of Cardiology, Brazilian society of hypertension, Brazilian Society of Nephrology. V Guidelines for ambulatory blood pressure monitoring (ABPM) and III Guidelines for home blood pressure monitoring (HBPM)]. Arq Bras Cardiol. 2011;97(3 Suppl 3):1-24.

25. Brazilian Association of Research Companies (BARC). Brazil Economic Classification Criterion. Available in: http://www.abep.org/. Accessed 24 Aug 2016.

26. Hallal PC, Matsudo SM, Matsudo VK, Araújo TL, Andrade DR, Bertoldi AD. Physical activity in adults from two Brazilian areas: similarities and differences. Cad Saude Publica. 2005;21(2):573-80. 
27. Barry KL, Fleming MF. The Alcohol Use Disorders Identification Test (AUDIT) and the SMAST-13: predictive validity in a rural primary care sample. Alcohol Alcohol. 1993;28(1):33-42.

28. Babor TF, Higgins-Biddle JC. Alcohol screening and brief intervention: dissemination strategies for medical practice and public health. Addiction. 2000;95(5):677-86.

29. Report of a WHO Consultation on Obesity. Obesity: preventing and managing the global epidemic. Geneva: World Health Organization (WHO Technical Report Series, No. 894); 2000.

30. Morisky DE, Green LW, Levine DM. Concurrent and predictive validity of a self-reported measure of medication adherence. Med Care. 1986;24(1):67-74

31. Ben AJ, Neumann CR, Mengue SS. The Brief Medication Questionnaire and Morisky-Green test to evaluate medication adherence. Rev Saude Publica. 2012;46(2):279-89.

32. Svarstad BL, Chewning BA, Sleath BL, Claesson C. The Brief Medication Questionnaire: a tool for screening patient adherence and barriers to adherence. Patient Educ Couns. 1999:37(2):113-24.

33. Charlson ME, Pompei P, Ales KL, Mackenzie CR. A new method of classifying prognostic comorbidity in longitudinal studies: development and validation. J Chronic Dis. 1987:40(5):373-83.

34. Friedewald WT, Levy RI, Fredrickson DS. Estimation of the concentration of low-density lipoprotein cholesterol in plasma, without use of the preparative ultracentrifuge. Clin Chem. 1972;18(6):499-502.

35. Sposito AC, Caramelli B, Fonseca FA, Bertolami MC, Afiune Neto A, Souza AD, Lottenberg AM, Chacra AP, Faludi AA, Loures-Vale AA, et al. IV Brazilian Guideline for Dyslipidemia and Atherosclerosis prevention: Department of Atherosclerosis of Brazilian Society of Cardiology. Arq Bras Cardiol. 2007;88 Suppl 1:2-19.

36. UKPDS Risk Engine. In. https://www.dtu.ox.ac.uk/riskengine/. Accessed 24 Aug 2016.

37. Jafar TH, Hatcher J, Poulter N, Islam M, Hashmi S, Qadri Z, Bux R, Khan A, Jafary FH, Hameed A, et al. Community-based interventions to promote blood pressure control in a developing country: a cluster randomized trial. Ann Intern Med. 2009;151(9):593-601.

38. Jafar TH, Levey AS, Jafary FH, White F, Gul A, Rahbar MH, Khan AQ, Hattersley A, Schmid CH, Chaturvedi N. Ethnic subgroup differences in hypertension in Pakistan. J Hypertens. 2003:21 (5):905-12.

39. McLean DL, Simpson SH, McAlister FA, Tsuyuki RT. Treatment and blood pressure control in 47,964 people with diabetes and hypertension: a systematic review of observational studies. Can J Cardiol. 2006;22(10):855-60.

40. Guirado EA, Ribera EP, Huergo VP, Borras JM, Group A. Knowledge and adherence to antihypertensive therapy in primary care: results of a randomized trial. Gac Sanit. 2011;25(1):62-7.

41. Maruf FA, Akinpelu AO, Salako BL. Effects of aerobic exercise and drug therapy on blood pressure and antihypertensive drugs: a randomized controlled trial. Afr Health Sci. 2013;13(1):1-9.

42. Harris MF, Fanaian M, Jayasinghe UW, Passey ME, McKenzie SH, Powell Davies G, Lyle DM, Laws RA, Schütze H, Wan Q. A cluster randomised controlled trial of vascular risk factor management in general practice. Med J Aust. 2012:197(7):387-93.

43. Doucette WR, Witry MJ, Farris KB, McDonough RP. Community pharmacistprovided extended diabetes care. Ann Pharmacother. 2009;43(5):882-9.

44. Kramer MK, Kriska AM, Venditti EM, Miller RG, Brooks MM, Burke LE, Siminerio LM, Solano FX, Orchard TJ. Translating the Diabetes Prevention Program: a comprehensive model for prevention training and program delivery. Am J Prev Med. 2009;37(6):505-11.

45. Qureshi NN, Hatcher J, Chaturvedi N, Jafar TH, Group HR. Effect of general practitioner education on adherence to antihypertensive drugs: cluster randomised controlled trial. BMJ. 2007:335(7628):1030.

\section{Submit your next manuscript to BioMed Central and we will help you at every step:}

- We accept pre-submission inquiries

- Our selector tool helps you to find the most relevant journal

- We provide round the clock customer support

- Convenient online submission

- Thorough peer review

- Inclusion in PubMed and all major indexing services

- Maximum visibility for your research

Submit your manuscript at www.biomedcentral.com/submit

) Biomed Central 